\title{
COMPETÊNCIAS E APRENDIZAGEM EMPREENDEDORA EM MPE'S EDUCACIONAIS
}

\author{
ENTREPRENEURIAL COMPETENCES AND LEARNING IN EDUCATIONAL MSE'S
}

Recebido em 13.01.2013. Aprovado em 22.09.2014 Avaliado pelo sistema double blind review

DOI: http://dx.doi.org/10.12712/rpca.v8i3.335

\author{
Marcia Aparecida Zampier \\ marciazampier@gmail.com \\ Universidade Estadual do Centro-Oeste - Guarapuava - PR - Brasil
}

\section{Adriana Roseli Wünsch Takahashi}

adrianarwt@terra.com.br

Universidade Federal do Paraná - Curitiba - PR - Brasil

\section{Resumo}

Este estudo, realizado com proprietários e gestores de MPE's do setor educacional privado de Curitiba, teve o propósito de analisar de que maneira as competências empreendedoras de oportunidade e administrativas foram desenvolvidas por meio de um processo de aprendizagem empreendedora. A metodologia consistiu em um estudo exploratório, com abordagem qualitativa e perspectiva temporal de corte transversal com aproximação longitudinal. Realizou-se um estudo de multicasos (nove). Como resultado, foi possível identificar o desenvolvimento das competências de oportunidade e administrativa e o processo de aprendizagem empreendedora e constatar que a competência administrativa foi desenvolvida com um grau ligeiramente superior à de oportunidade. Quanto às proposições da autora, algumas foram confirmadas totalmente, outras parcialmente e outras não puderam ser confirmadas. Além disso, foi possível apresentar uma proposta de aprimoramento do modelo conceitual utilizado.

Palavras-chave: Aprendizagem Empreendedor. Competência Empreendedora. Setor Educacional.

\begin{abstract}
The present study, with owners and managers of MSE's in the private education sector in Curitiba, had the objective of analyzing in which way the entrepreneurs' competences of managing and opportunities were developed through an entrepreneur learning process. The methodology consisted in a qualitative approach and temporal perspective of cross-sectional with longitudinal approximation. A multi-case study was conducted (nine). As the result, it was possible to verify that the development of opportunity and management and the process of entrepreneurial learning, and to find out the managing competence was developed with a slight superior degree in relation to the opportunity one. Regarding to the author's proposals, some were totally confirmed, others only partially confirmed and some others could not be confirmed at all within this study. It was possible to present a suggestion of a way to refine of the entrepreneur learning concept model.
\end{abstract}

Keywords: Entrepreneurial Learning. Entrepreneurial Competences. Educational Sector. 


\section{Introdução}

Tratar do desenvolvimento de competências em organizações de pequeno porte e do processo de aprendizagem do empreendedor demanda levar em conta a literatura das categorias selecionadas (competências e aprendizagem), as especificidades da área (o empreendedorismo) e as particularidades do setor (educacional).

Em 2013 o professor de empreendedorismo Dr. Andreas Kuckertz da Universidade de Hohenheim, Alemanha, conduziu uma pesquisa internacional com 196 especialistas no tema, em diversos países, com o objetivo de identificar os tópicos e métodos relevantes (hot topics) no campo de empreendedorismo. De acordo com esta pesquisa, os tópicos atuais mais relevantes são: processo empreendedor, empreendedorismo social, e pensamento e comportamento empreendedor. Os resultados das questões abertas foram classificados em 14 categorias e subcategorias (KUCKERTZ, 2013). A categoria de comportamento empreendedor tem a aprendizagem empreendedora como subcategoria, evidenciando a atualidade e relevância da abordagem deste trabalho. Dado que a literatura de aprendizagem organizacional já tem evidenciado teórica e teórico-empiricamente que o processo de aprendizagem resulta em competências e que as competências expressam o processo de aprendizagem, esta proposição já validada pode ser transposta para o campo do empreendedorismo, a fim de contribuir para o avanço do conhecimento em aprendizagem empreendedora e competência empreendedora.

Wang e Chug (2013) afirmam que aprendizagem empreendedora é um importante conceito que nasceu da interface entre empreendedorismo e aprendizagem organizacional. Da análise da produção sobre o tema, os autores identificaram que é necessário o desenvolvimento teórico e empírico na área, bem como identificaram os temas chave de pesquisa atualmente que merecem mais atenção em futuras pesquisas (gaps) sobre aprendizagem empreendedora: aprendizagem individual e coletiva, aprendizagem exploratory e exploitative, e aprendizagem intuitiva e sensing.

A pesquisa de Kuckertz (2013), já citada, evidenciou também a relevância e o potencial de estudos com metodologias qualitativas, uma vez que há um predomínio de estudos quantitativos. Desta forma, este trabalho procura também contribuir por meio da adoção deste delineamento metodológico, que é pertinente a abordagem processual adotada. Outra contribuição presente neste artigo diz respeito a originalidade do setor escolhido, educacional, que não foi investigado amplamente na literatura consultada.

O empreendedorismo gera impactos na sociedade, produzindo empregos, gerando rendas, proporcionando crescimento e desenvolvimento (ESPEJO e PREVIDELLI, 2006). De acordo com o Global Entrepreneurship Monitor - GEM 2008 (2009), a população brasileira é classificada como uma das mais empreendedoras do mundo, ocupando o 13을. lugar. Porém, deve-se ter em vista que a maioria dos empreendimentos no Brasil é realizada por necessidade, enquanto em outros países se identifica um predomínio de empreendimentos por oportunidade. Entretanto, em micros e pequenas empresas - MPE's do setor educacional, a motivação do empreendimento por necessidade parece não ser preponderante; porquanto, de acordo com a pesquisa de Takahashi, Graeff e Teixeira (2006), os empreendedores investem em seus próprios negócios por dois motivos: a) como opção de carreira a fim de realizar-se pessoal e profissionalmente e b) para aproveitar a oportunidade de investimentos no setor educacional privado, cuja demanda aumentou em face do enfraquecimento dos investimentos públicos na educação nas últimas décadas, tornando-o um setor emergente.

Independente da motivação para a criação de novos empreendimentos é necessário conduzi-los 
de forma satisfatória para obter sucesso. Para tal, Dias, Nardelli e Vilas Boas (2008) sugerem que os empreendedores precisam contar com ampla variedade de conhecimentos e de habilidades sociais, as quais envolvem um conjunto de competências que permitem aos indivíduos interagir uns com os outros. Neste sentido, Bittencourt (2005) destaca que o desenvolvimento de competências possibilita que as práticas organizacionais sejam direcionadas para uma gestão mais efetiva e propícia à estratégia competitiva.

Nesse contexto, Feuerschütte e Godoi (2007) constataram que o empreendedor exerce um papel fundamental, pois é o responsável pelas ações e pelo sucesso de seus empreendimentos. Para desenvolver e ampliar as competências empreendedoras desses indivíduos, Bitencourt (2005) e Freitas e Brandão (2006) salientam a relevância do processo de aprendizagem; afinal, não há desenvolvimento sem aprendizagem, e esta se constitui numa evolução necessária para a aquisição de competências. Assim, a aprendizagem é vista como competência e o conhecimento como um recurso especial, sendo ambos os fatores chaves para a atuação na dinâmica organizacional e na sociedade (ANTAL et al., 2001).

De acordo com Le Boterf (2003), a competência se expressa na ação em um determinado contexto, a partir de conhecimentos e experiências que se acumulam e potencializam os recursos de cada indivíduo (FEUERSCHÜTTE e ALPERSTEDT, 2008). Quanto à aprendizagem, Politis (2005) alerta para o fato de que somente estudar os seus resultados com experiências prévias dos empreendedores é de pouca relevância para o campo, pois é necessário incluir conceitos e teorias que explorem a aprendizagem empreendedora como um processo experiencial e também como o mesmo evolui ao longo da carreira.

Cabe ressaltar assim, que foi possível identificar uma lacuna na literatura que relacione as categorias de aprendizagem e competências no contexto empreendedor, de forma geral, e no setor educacional, em específico. Da mesma forma, não foi identificado na literatura a aplicação do modelo aqui adotado no contexto nacional.

O aumento das escolas particulares nos últimos anos chama a atenção para a necessidade de uma gestão escolar eficiente que gere vantagem competitiva frente à concorrência acirrada. 0 setor educacional emergente, desperta o interesse dos empreendedores em investir no ramo, ampliando-se o número de MPE's.

Pretende-se assim compreender como ocorre o processo de aprendizagem no contexto empreendedor por meio da investigação da transformação de suas experiências em conhecimento, e como este processo implica no desenvolvimento de determinadas competências - a saber: as competências de (a) identificar oportunidades e (b) de lidar com os desafios do negócio na organização - de proprietários/dirigentes de instituições de ensino privadas de Curitiba-PR (MPEs).

\section{Competências Empreendedoras}

Segundo Mamede e Moreira (2005, p. 4), “a competência empreendedora pode ser tratada tanto como competência do indivíduo, quanto relacionada à prática administrativa, devido às diferentes tarefas que desempenham". Desta forma, os conceitos de competência empreendedora derivam dos conceitos já existentes na vertente individual, que privilegiam a experiência e a construção do conhecimento subjacente a elas.

A partir dos conceitos apresentados por teóricos representantes de estudos nesta categoria, assumiu-se neste trabalho que competências empreendedoras são consideradas como um corpo de conhecimento, área ou habilidade, qualidades pessoais ou características, atitudes ou visões, 
motivações ou direcionamentos, que podem, de diferentes formas, contribuir para o pensamento ou ação efetiva do negócio (SNELL e LAU, 1994), e que viabilizam a um indivíduo imprimir ações, estratégias e sua visão na criação de valor, tangíveis e intangíveis, para a sociedade. (ANTONELLO, 2005).

Dutra (2004), ao tratar do conceito de competências, apresenta duas vertentes: as capacidades ou inputs, que consistem nos conhecimentos, habilidades, atitudes e valores (CHAV), como um estoque do indivíduo, e sua efetiva entrega à organização de forma a agregar valor. Assim, o autor destaca que uma noção constitutiva do conceito de competências é a noção de complexidade. Ela refere-se ao nível de abstração com que um profissional realiza seu trabalho. Nesta ótica, a competência é tanto mais pronunciada quanto mais é articulada e mobilizada em contextos mais complexos (DUTRA, 2004).

Dentro do tema de competências empreendedoras, alguns autores têm se preocupado em criar tipologias ou modelos que possibilitam a identificação por parte dos pesquisadores, dos conhecimentos, habilidades e atitudes, enfim, das competências necessárias ao desenvolvimento de suas atividades. Dentre eles, dois trabalhos foram identificados na literatura: o de Cooley (1990) e o de Man e Lau (2000).

A classificação de Cooley (1990), voltada para os empreendedores, foi revisada e adaptada do modelo de competências de McClelland e contém uma lista com 10 competências empreendedoras, dentre elas: busca de oportunidade e iniciativa; persistência; comprometimento; exigência de qualidade e eficiência; correr riscos calculados; estabelecimento de metas; busca de informações; planejamento e monitoramento sistemáticos; persuasão e rede de contatos; independência e autoconfiança.

Para Man e Lau (2000), a competitividade na micro e pequena empresa - MPE é fortemente influenciada pelas competências do empreendedor. Partindo deste pressuposto, os autores realizaram estudos empíricos entre 1993 e 1999 que resultaram em uma categorização de competências em seis áreas distintas, envolvendo: competências de oportunidade, relacionamento, conceituais, administrativas, estratégicas e de comprometimento.

Zampier, Takahashi e Fernandes (2009) alertam para o fato de que, no modelo de Cooley (1990) e no modelo de Man e Lau (2000), nem tudo que os autores classificam como competências parecem ser, a rigor, competências conforme aponta a literatura. Por exemplo, comprometimento, persistência, independência e autoconfiança, são termos que parecem manifestar na realidade atitudes ou mesmo traços de personalidade ou ainda comportamentos. Estas ponderações foram consideradas na seleção das competências estudadas.

Vários estudos utilizando os modelos relatados foram identificados, nos quais as competências empreendedoras predominantes envolvem as áreas de oportunidade e gestão. Tal ênfase parece convergir com os principais temas de pesquisa em empreendedorismo, que tem atraído a atenção dos pesquisadores nas últimas décadas em face das características particulares dos empreendedores e das suas dificuldades na criação e desenvolvimento de novos negócios. Alguns estudos destacam também que o desenvolvimento das competências está associado a um processo de aprendizagem (BITENCOURT, 2005; FEUERSCHÜTTE e GODOI, 2007; BARINI FILHO, 2008), mas não o explicam no contexto empreendedor.

\section{Aprendizagem Empreendedora}

A partir da literatura consultada sobre esta categoria, foi possível chegar ao conceito que foi adotado neste estudo: aprendizagem empreendedora é um processo contínuo que facilita o 
desenvolvimento de conhecimento necessário para começar novos empreendimentos e administrá-lo, sendo os conhecimentos advindos da experiência pessoal do empreendedor e utilizados para guiar a escolha de novas experiências (POLITIS, 2005). Boa parte do aprendizado é alcançada através das ações, ou seja, na prática (POLITIS, 2005), de forma experiencial (MORRISON e BERGIN-SEERS, 2002) e advém das experiências passadas de sucesso e insucesso, da observação de outros empreendedores e de outras fontes de relacionamentos (RAE, 2005; MAN, 2006; LÉVESQUE, MINNITI e SHEPHERD, 2009). Esta aprendizagem "representa o meio pelo qual se adquire a competência, enquanto a competência representa a manifestação do que o indivíduo aprendeu” (FREITAS e BRANDÃO, 2006, p. 100).

Na literatura consultada foram identificados alguns autores que elaboraram modelos de análises do processo de aprendizagem empreendedora, com o objetivo de entender esse processo, como se verifica na sequência.

\section{Modelos de Aprendizagem Empreendedora}

O primeiro modelo identificado na literatura foi o Modelo para Investigação e Análise do Processo de Aprendizagem Empreendedora de Moraes e Hoeltgebaum (2003), em que as autoras relatam que, para compreender como os empreendedores de fato aprendem, é preciso, além de entender como eles se tornam empreendedores, entender como eles gerenciam o seu próprio negócio e como atuam estrategicamente; portanto envolve a identificação de oportunidade e a administração da empresa criada.

A segunda referência encontrada foi a de Rae (2004), que considera o indivíduo dentro do seu contexto social e abrange três dimensões: a) formação pessoal e social; b) aprendizagem contextual; c) empreendimento negociado. Portanto, esse modelo ilustra o processo de aprendizagem e formação da identidade, as práticas sociais emergentes e as negociações que ocorrem durante a aprendizagem empreendedora. Esses temas foram subdivididos em outros subtemas e o modelo foi testado empiricamente em diversos estudos realizados pelo próprio autor.

0 terceiro modelo identificado na literatura de aprendizagem empreendedora é o de Politis (2005), que evidencia um processo de transformação de experiência em conhecimento. Essa autora argumenta que a experiência, e em particular, a experiência anterior em criação de negócios, é importante para a aprendizagem empreendedora, pois os conhecimentos advêm dessas experiências e influenciam as escolhas estratégicas feitas pelos empreendedores.

O modelo de Politis (2005) está demonstrado na figura 1, tendo em vista que foi adotado neste estudo, pois parece ser o modelo que permite estabelecer uma ponte com a categoria de competências empreendedoras. A própria autora relata que pouca atenção era dedicada até então para descobrir como empreendedores, por meio de suas experiências, desenvolvem habilidades e conhecimento que os habilita a reconhecer e agir nas oportunidades e a administrar novos empreendimentos, além de como desenvolvem o conhecimento empreendedor que impacta no desempenho de um negócio posterior. 


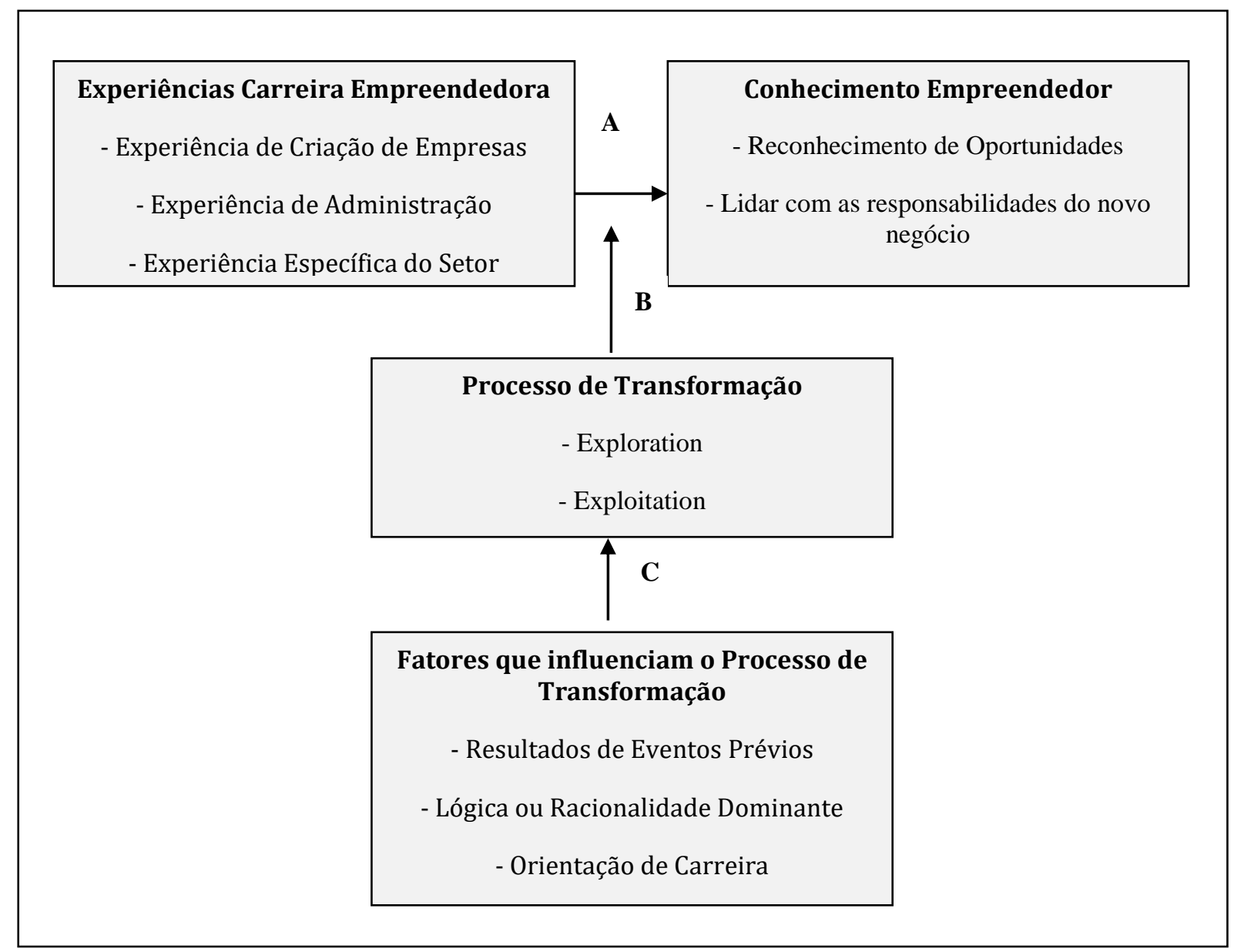

Figura 01 - Estrutura conceitual de aprendizagem empreendedora como um processo experiencial. Fonte: Politis (2005, p. 402).

Seguindo a sequencia proposta por Politis (2005) em seu modelo conceitual, a primeira categoria a ser considerada é a do conhecimento empreendedor.

Conhecimento Empreendedor: Quando a aprendizagem é aplicada ao conceito de empreendedorismo, tem-se referido a como reconhecer uma oportunidade e como agir ao encontrá-la, além de aprender como superar obstáculos na organização e administração de novos negócios, enfrentando as responsabilidades oriundas desse novo negócio.

O conhecimento está estruturado através da prática e da observação e é resultante do processo de aprendizagem que ocorre através do tempo, sofrendo mudanças e gerando outras no comportamento dos indivíduos (LEZANA e TONELLI, 1998). Portanto as pessoas adquirem conhecimento de três formas: a) pela experiência direta, b) por observar as ações dos outros e suas consequências e, c) por explicitar em fontes como livros, artigos, entre outros (HOLCOMB et al., 2009).

Experiências da Carreira do Empreendedor: A experiência prévia em criação de novos negócios pode prover o empreendedor com insights sobre como desenvolver e financiar novas organizações, produtos ou serviços, como contratar e liderar pessoas e como atrair e manter consumidores (POLITIS, 2005; 2008). Os três tipos de experiências relevantes na carreira dos empreendedores são: experiência em criação de novas empresas, experiência em gestão e experiência no ramo específico em que se pretende atuar. Cada um desses tipos facilita a aquisição de conhecimento que podem ajudar a resolver problemas similares no futuro. As 
seguintes proposições foram elaboradas por Politis (2005, p. 406-407) para sumariar os pressupostos referentes ao desenvolvimento do conhecimento derivado destas experiências: Proposição 1: A experiência de carreira do empreendedor, em termos de criação de empresas, gestão e experiência específica do setor é positivamente relacionada ao desenvolvimento do conhecimento empreendedor.

Proposição 1a: Quanto maior a experiência de carreira, maior é a eficácia do empreendedor em reconhecer e agir nas oportunidades empreendedoras.

Proposição 1b: Quanto maior a experiência de carreira, maior é a eficácia do empreendedor em lidar com os desafios de novos negócios.

No entanto como essas experiências são transformadas em conhecimentos depende do processo de transformação predominante do empreendedor.

Processo de Transformação de Aprendizagem Empreendedora: Politis (2005) argumenta que quando se estuda o processo de aprendizagem empreendedora, é importante reconhecer que o modelo cíclico de Kolb não é plenamente adequado para entender a complexidade e as incertezas dos empreendedores, tendo em vista que este processo não necessariamente segue um ciclo pré-determinada, justificando assim a criação do seu modelo.

A aprendizagem empreendedora é um processo experiencial no qual a experiência de carreira de um empreendedor é transformada em conhecimento por meio do equilíbrio entre o exploitation do que ele já sabe e do exploration de novas possibilidades (POLITIS e GABRIELSSON, 2005), e esse conhecimento pode ser usado para guiar as escolhas de novas experiências. De acordo com March (1991), exploitation refere-se à exploração do que já é conhecido, ou seja, de velhas certezas, nas quais os empreendedores podem escolher ações que replicam os seus conhecimentos existentes com o objetivo de obter vantagens, reduzir custos e maximizar benefícios, incluindo refinamento, rotina e implementação de conhecimento, execução, produção e escolhas; exploration é o meio pelo qual os indivíduos aprendem com experiências de explorar novas possibilidades, descobertas e inovação que são distintas das anteriores (WEICK e WESTLEY, 1996; POLITIS, 2005).

Nenhum desses dois modos de transformar experiência em conhecimento é automaticamente melhor que o outro, pois de acordo com March (1991), os dois são essenciais para sustentar a aprendizagem, sendo necessário então manter um equilíbrio entre ambos, visando à prosperidade. Com base nestes conceitos, Politis (2005) afirma que o modo predominante de transformação de experiência em conhecimento dos empreendedores pode moderar a relação entre a sua experiência de carreira e o desenvolvimento de conhecimento empreendedor. Com base nesta relação, Politis (2005, p. 410) apresenta três proposições:

Proposição 2: 0 modo predominante de transformação de um empreendedor modera a relação entre sua experiência de carreira e o conhecimento empreendedor.

Proposição 2a: Quanto maior a confiança em exploration como modo de transformação predominante, mais efetivo é o empreendedor em reconhecer e agir nas oportunidades.

Proposição 2b: Quanto maior a confiança em exploitation como modo de transformação predominante, mais efetivo é o empreendedor em enfrentar as responsabilidades do negócio.

Estes processos de transformação das experiências em conhecimento empreendedor são 
influenciados por determinados fatores, descritos a seguir.

- Fatores que influenciam o processo de transformação da experiência em conhecimento: Politis (2005) identificou três fatores que podem auxiliar a compreender o modo predominante dos empreendedores de transformar experiência em conhecimento empreendedor, e destes fatores derivou as respectivas proposições do modelo:

i) resultados de eventos empreendedores prévios: quer sejam com experiências bem sucedidas ou com insucesso, pois podem ser replicados quando positivos e evitados quando negativos. Assim Politis (2005, p. 412) apresenta as três seguintes proposições:

Proposição 3: 0 resultado de eventos empreendedores prévios de um empreendedor está relacionado ao seu modo de transformar uma experiência em conhecimento.

Proposição 3a: Quanto maior o grau de fracasso empreendedor passado, maior o grau de um modo explorative de transformar uma experiência em conhecimento.

Proposição 3b: Quanto maior o grau de sucesso empreendedor passado, maior o grau de um modo exploitative de transformar uma experiência em conhecimento.

ii) lógica ou racionalidade dominante de um empreendedor: segundo Sarasvathy (2001) há 2 tipos na teoria econômica: causação e efetuação. 0 raciocínio causal usa técnicas de análise e estimativa para explorar mercados latentes. Foca no que deve ser feito de acordo com as metas pré-determinadas. Já a lógica de efetuação não começa com metas pré-estabelecidas, mas seguem metas que emergem com o tempo, de acordo com aspirações do fundador. Com base nesta classificação três proposições foram elaboradas por Politis (2005, p. 413):

Proposição 4: A racionalidade predominante de um empreendedor está relacionada ao seu modo de transformar uma experiência em conhecimento.

Proposição 4a: Quanto maior a confiança na efetuação como racionalidade dominante, maior o grau do modo explorative de transformar uma experiência em conhecimento.

Proposição 4b: Quanto maior a confiança na causação como racionalidade dominante, maior o grau do modo exploitative de transformar uma experiência em conhecimento.

iii) orientação de carreira de um empreendedor: são identificados quatro estilos: linear, especialista, espiral e transitória. A preferência por cada um desses estilos é baseada em diferentes motivos do empreendedor. Assim, enquanto alguns preferem explorar novas atividades, mudar de campo, de organização e de trabalho, outros preferem a rotina e a especialização (BROUSSEAU et al., 1996 apud POLITIS, 2005; POLITIS e GABRIELSSON, 2006). A partir destes quatro estilos e suas implicações na forma de aprendizagem, Politis (2005, p. 415), apresentou as seguintes proposições:

Proposição 5: A orientação de carreira de um empreendedor está relacionada ao seu modo de transformar uma experiência em conhecimento.

Proposição 5a: Empreendedores com uma orientação de carreira transitória ou espiral podem de forma mais ampla, focar em um modo explorative de transformar uma experiência em conhecimento.

Proposição 5b: Empreendedores com uma orientação de carreira linear ou especialista podem 
de uma forma mais ampla focar em um modo exploitative de transformar uma experiência em conhecimento.

O modelo apresentado indica ainda, por meio das setas, as relações existentes entre o processo de transformação das experiências em conhecimento. É esta ponte que permite a ligação de aprendizagem com competências no contexto empreendedor. A análise da aprendizagem empreendedora por meio deste processo de transformação (exploration and exploitation) está alinhado com um dos desafios futuros apontados por Wang e Chugh (2013) com base nas lacunas identificadas na literatura.

\section{Modelo Conceitual de Competências e Aprendizagem de Empreendedores}

A partir da revisão da literatura, constatou-se que o modelo de Politis (2005) explicita a ligação com o conceito de competências ao tratar o conhecimento empreendedor como a habilidade de reconhecer oportunidades e de lidar com as responsabilidades de um novo negócio, o que corresponde às competências empreendedoras do modelo de Man e Lau (2000), ou seja, as competências de oportunidade e administrativa. Assim, pressupõe-se que a investigação do processo de aprendizagem empreendedora por meio destes dois modelos representa uma estrutura com forte potencial explicativo para o desenvolvimento das duas competências, conforme se constata na figura 2.

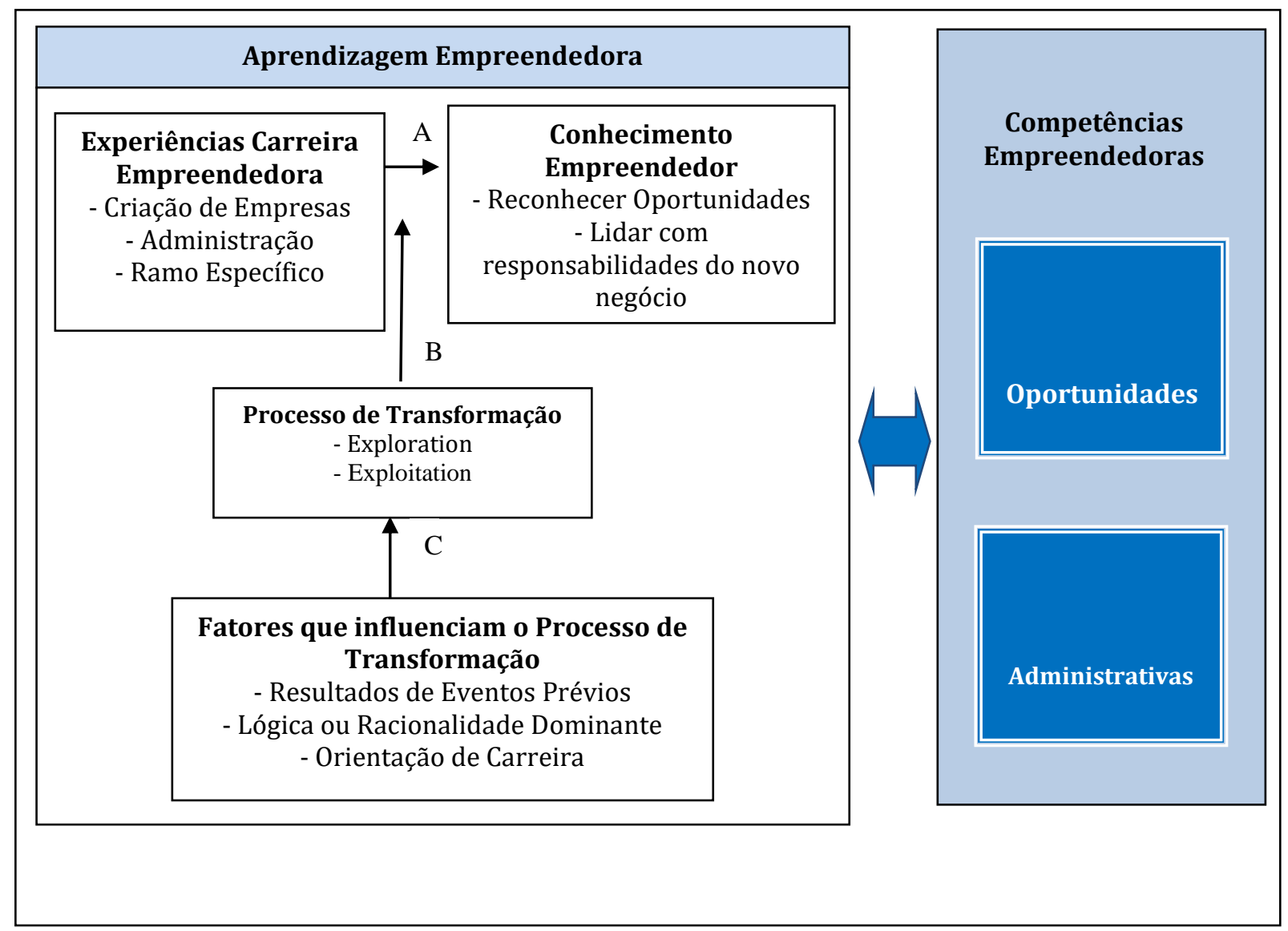

Figura 02 - Modelo conceitual de pesquisa

Fonte: Adaptado de Politis (2005) e Man e Lau (2000). 
Após a descrição do referencial teórico e do modelo elaborado na Figura 2, apresenta-se, na sequência, a metodologia que norteou este trabalho.

\section{Metodologia}

Este trabalho pode ser caracterizado como exploratório, tendo em vista a ausência de estudos teóricos e teórico-empíricos no Brasil que abordem a formação e o desenvolvimento das competências por meio do processo de aprendizagem no contexto empreendedor, utilizando como base as categorias de competências de oportunidade e administrativas do Modelo de Competências Empreendedoras de Man e Lau (2000) e o Modelo de Aprendizagem Empreendedora de Politis (2005).

A abordagem adotada foi a qualitativa (CRESWELL, 2007) e a perspectiva temporal de corte transversal (COLLIS e HUSSEY, 2005) com aproximação longitudinal (NEUMAN, 1999). A estratégia de pesquisa escolhida foi a de estudo de caso, mais especificamente, trata-se de um estudo de multicasos, pois estes possibilitam um aprofundamento no estudo dos dados e a previsão de resultados semelhantes ou contrastantes com base no que foi esperado no início da pesquisa (YIN, 2010).

O nível da análise foi organizacional e a unidade de análise individual. A seleção dos entrevistados foi não probabilística, por conveniência, acessibilidade e proximidade, pois se considerou a disponibilidade dos empreendedores em participar das entrevistas e também a proximidade. Os critérios de seleção foram que: as instituições pertencessem ao setor da educação, portanto de serviços; que estivessem enquadradas como micro ou pequena empresa, de acordo com os critérios do SEBRAE (2008), que levam em consideração o número de funcionários: micro empresa- até nove funcionários; pequena- entre 10 e 49 funcionários; que já fossem estabelecidas no mercado segundo a classificação do GEM 2008 (2009), já existindo a mais de 42 meses; e que os empreendedores fundadores atuassem na instituição como gestores ou dirigentes. Este recorte de porte assegurou o controle da variável complexidade, apontado por Dutra (2004).

Assim, por acessibilidade e proximidade, foram selecionadas as instituições de ensino particulares instaladas nos bairros: Alto Boqueirão, Boqueirão, Hauer e Xaxim. Esses quatro bairros juntos contêm 55 escolas particulares, das quais 12 são religiosas, associações, fundações e/ou ligadas a outras instituições, ficando de fora do presente estudo. Das 43 escolas restantes, 18 foram eliminadas da pesquisa por estarem fora dos critérios estabelecidos, ou seja, eram de médio e grande porte. Outras 16 instituições foram contatadas várias vezes, mas seus proprietários não quiseram participar do estudo. Finalmente, das 55 instituições, nove organizações aceitaram participar da pesquisa. Essas instituições foram codificadas de I1 a I9 e seus respectivos empreendedores de E1 a E9.

Assim, por se tratar de um estudo de caso qualitativo, exploratório e descritivo, os dados foram coletados em diversas fontes (primárias e secundárias), o que exigiu planejamento e preparação (YIN, 2010). Como dados secundários foram utilizados documentos, folhetos, folders, entre outros, além de informações sobre as organizações, quer sejam concedidas por elas próprias ou obtidas em seus sites na internet. Foram consultados Órgãos Públicos de Administração, Associações e Sindicatos do Sistema Educacional do Paraná, Legislação, catálogos telefônicos, jornais e artigos sobre o contexto do setor.

Como dados primários, estes foram obtidos por meio de observação não-participante do local e dos entrevistados, em que se procurou apreender aparências, eventos e/ou comportamentos 
(GODOY, 2006). Também foram realizadas entrevistas semi-estruturadas em profundidade baseadas em roteiro composto por questões abertas e fechadas, em que os entrevistados puderam expor suas opiniões com maior flexibilidade.

Os empreendedores foram entrevistados no mês de outubro de 2009. Tais entrevistas foram realizadas nas próprias organizações, sendo gravadas com autorização dos participantes e, posteriormente, transcritas e codificadas, para a realização das análises. A duração média das entrevistas foi de uma hora e vinte minutos e a transcrição totalizou 139 laudas.

Os dados foram analisados segundo as técnicas de análise de conteúdo que foi resgatando, por meio da entrevista, a história de vida dos empreendedores. Mais especificamente, utilizou-se da análise temática que, segundo Bardin (1977, p. 105) consiste em "descobrir os 'núcleos de sentido' que compõem a comunicação e cuja presença, ou frequência de aparição podem significar alguma coisa para o objetivo analítico escolhido", tendo em vista que o tema é "geralmente utilizado como unidade de registro para estudar motivações de opiniões, de atitudes, de valores, de crenças, de tendências, etc". A seguir, considerando o delineamento da pesquisa e os dados tratados, apresentam-se os resultados.

\section{Apresentação e Análise dos Resultados}

Os resultados aqui apresentados derivam de padrões encontrados em nove casos que foram previamente analisados individualmente, segundo o modelo adotado. Entretanto, por questões de limitação de espaço, serão apresentados os resultados finais.

\section{Perfil}

Quanto ao perfil das nove instituições participantes da pesquisa de campo, duas se enquadram como micro empresa e sete como pequenas empresas, de acordo com critérios do SEBRAE (2008). Juntas, elas empregavam, no momento da coleta de dados em 2009, 187 pessoas que atendiam 1158 alunos matriculados entre o berçário e o último ano do ensino médio, 176 alunos no ensino à distância, englobando os cursos de graduação e pós- graduação na área de educação, administração e direito, totalizando 1334 alunos. Elas possuem pelo menos um dos empreendedores fundadores atuando na instituição como gestor ou dirigente e todas se enquadram dentro dos critérios estabelecidos para este estudo.

Os principais padrões encontrados no perfil dos empreendedores correspondem ao fato de a maioria ser do sexo feminino, ser casada, ter alto grau de escolarização, com muito tempo de experiência, ser dedicado e ter escolhido a área educacional por afinidade, tendo em vista que já atuavam anteriormente na mesma área.

\section{Avaliação das competências pelos empreendedores}

Foi solicitado que os empreendedores fizessem uma auto-avaliação das suas competências administrativas e de oportunidade, tendo como base sua posição em relação aos seus concorrentes, por meio de um quadro com base na escala de Likert de cinco pontos, variando de muito baixa a muito alta. A maioria dos empreendedores avaliou suas competências como na média ou alta. Apenas dois deles divergiram, um por classificá-las como baixa (E1) e outro como muito alta (E3). Em seguida, os empreendedores narraram diversas ações relacionadas à essas competências, as quais possibilitaram analisar sua convergência ou não com suas práticas.

Houve divergência na avaliação das competências pelos empreendedores e pela pesquisadora em oito casos. Na maioria dessas divergências, a avaliação da pesquisa apontou, com base nos 
relatos, um grau de desenvolvimento maior do que o indicado pelos empreendedores, exceto em E3. A partir desses resultados, optou-se por considerar a avaliação da pesquisadora para as análises. Com base na identificação da presença e intensidade destas competências entre os empreendedores, buscou-se analisar cada etapa do que constitui um processo de aprendizagem empreendedora, segundo o modelo adotado, para depois correlacionar os achados com uma possível explicação para os níveis encontrados de desenvolvimento das competências.

\section{Experiências da Carreira Empreendedora}

A primeira categoria investigada foi a experiência da carreira dos empreendedores em criação de empresas, gestão de empresas e na área educacional. Constatou-se então que a maioria dos empreendedores que abriram suas instituições na área educacional, o fizeram baseados em experiências anteriores (POLITIS, 2005), pois sete dentre os nove já tinham experiência na área em cargos de direção ou como professores, convergindo com os resultados da pesquisa de Takahashi, Graeff e Teixeira (2006).

A princípio, as duas proposições da autora puderam ser confirmadas, embora neste setor a segunda proposição se expressa de forma mais acentuada. Oito entre os nove empreendedores entrevistados tinham algum tipo de experiência prévia, quer em criação de mais de uma empresa (E1, E3, E4), quer em gestão de outras empresas inclusive em outros ramos, escolas públicas ou igrejas (E1, E2, E3, E4, E5), quer na área educacional, como professores ou diretores (E2, E3, E4, E5, E6, E8, E9). Apenas a empreendedora E7 não tinha nenhum tipo de experiência prévia. 0 fato de esses empreendedores possuírem experiência parece ter ajudado a identificar novas oportunidades de mercado e ter facilitado a lidar com as responsabilidades e enfrentar os desafios de uma organização escolar, conforme as proposições 1, 1a e $1 b$ de Politis (2005), que relaciona a intensidade da experiência em carreira com a eficácia do empreendedor para reconhecer e agir nas oportunidades empreendedoras e com a eficácia em lidar com os desafios de novos negócios.

\section{Conhecimento Empreendedor}

Continuando com a análise dos dados coletados e o modelo adotado, a segunda categoria investigada foi a do conhecimento empreendedor. De acordo com a literatura estudada, a aprendizagem se refere a aprender como reconhecer oportunidades e como agir ao encontrá-las (POLITIS, 2005), assim como aprender a superar os desafios relacionados à administração do novo negócio. Neste estudo foram identificados vários conhecimentos adquiridos pelos empreendedores, quer em toda sua carreira profissional, quer no período em que estão à frente das instituições pesquisadas.

Com relação aos conhecimentos administrativos percebeu-se que os predominantes foram os relacionados à área educacional, como por exemplo, proposta político-pedagógica e regimento escolar; seguidos pela administração escolar e gestão de pessoas. Alguns entrevistados também relataram os conhecimentos adquiridos em planejamento, finanças, contabilidade, marketing e treinamento, os quais fazem parte da rotina administrativa.

Na categoria administrativa, a média (55,56 \%) foi ligeiramente maior do que na categoria de identificar oportunidades (44,44\%), pois mais empreendedores foram avaliados como alto e muito alto na primeira, apresentando uma gama de conhecimentos desenvolvidos em gestão. Uma das possíveis explicações poderia ser as particularidades setor, que condiz com o fato de permanecerem neste negócio por tantos anos (entre cinco e 22 anos), que tem transformado as 
experiências em conhecimentos administrativos, em lidar com o negócio, de forma mais intensa do que procurar novas oportunidades neste setor ou em outros.

Quanto às competências de oportunidade, foi possível verificar que os empreendedores deste setor se restringem ao próprio negócio e à intenção de permanecer nele, ampliando a estrutura física, implantando novos cursos presenciais ou à distância ou ainda, criando uma nova escola em outro local, com uma visão e diferenciada. Assim, os conhecimentos em relação a oportunidades ficaram circunscritos na esfera do próprio setor.

De acordo com o relato dos entrevistados, esses conhecimentos adquiridos ajudaram a desenvolver certas habilidades que lhes proporcionam maior rendimento e melhor desempenho em suas atividades, bem como auxiliaram a lidar melhor com os desafios do empreendimento. As habilidades mais citadas foram relacionadas à gestão: liderança; segurança e tranquilidade; tomada de decisão; melhoria nos relacionamentos; análise e reflexão; jogo de cintura e paciência. As habilidades relacionadas à identificação de oportunidades no mercado estão relacionadas principalmente à análise de novos investimentos e à percepção das mudanças que estão ocorrendo na sociedade e, consequentemente, nas necessidades das famílias e das crianças, como por exemplo, manter as crianças em tempo integral na escola e ofertar atendimentos diferenciados.

Com os conhecimentos adquiridos e as habilidades desenvolvidas, os empreendedores relataram que mudaram algumas de suas atitudes frente à identificação de oportunidades, à administração do negócio e das pessoas, as quais estão lhe proporcionando maior satisfação e melhor desempenho, dentre elas destacaram: na área administrativa - ouvir as pessoas; lidar com o público e ser sociável; na identificação de oportunidades - acompanhar mudanças e identificar novos nichos dentro do setor educacional.

Com o crescimento do número de escolas ao longo dos últimos anos, as habilidades e as atitudes dos gestores foram sendo cada vez mais demandadas. A competitividade do setor justifica o resultado de que as competências situam-se entre média e alta, pois os dados mostram que há uma preocupação em aplicá-las. Os empreendedores parecem realizar uma entrega efetiva de seus conhecimentos, habilidades e atitudes de diferentes formas, contribuindo para o pensamento e ação do negócio (SNELL e LAU, 1994), agregando valor à instituição e adequandose às novas realidades cada dia mais complexa e exigentes (DUTRA, 2004), e imprimindo ações e estratégias na criação de valor (ANTONELLO, 2005).

Contudo, de acordo com o modelo de aprendizagem empreendedora de Politis (2005), não basta se apontar os conhecimentos resultantes da experiência da carreira (A) para compreender o processo de aprendizagem empreendedora e, portanto, do desenvolvimento de competências. A ênfase tem de estar no processo de transformação das experiências em conhecimento (B) e nos fatores que influenciam esse processo de transformação (C).

\section{Processo de Transformação}

Na pesquisa em questão, para fazer a análise proposta de explicar os meios pelos quais ocorre esta transformação, identificou-se primeiramente, como os empreendedores aprendem. 0 padrão de práticas encontrado no processo de aprendizagem dos empreendedores entrevistados, a partir de suas citações, foi: a prática do dia-a-dia, estudos, cursos e palestras, leituras, experiência, erros e acertos, intuição, observação e relacionamento com os outros (RAE, 2005; MAN, 2006; LÉVESQUE e MINNITI; SHEPHERD, 2009). Observou-se ainda que as 
experiências dos três tópicos do modelo adotado (criação de empresas, administração e no setor específico) revelaram conhecimentos apreendidos.

Assim, constatou-se que, neste caso, o aprendizado ocorre por meio do processo experiencial (MORRISON e BERGIN-SEERS, 2002). Percebe-se então, que todos os empreendedores citam a experiência, representada aqui pela prática do dia-a-dia, como fonte de conhecimento. Portanto, aplicam conhecimentos advindos da transformação das experiências, confirmando que a abordagem experiencial é útil para analisar processos de aprendizagem empreendedora e confirmando a pertinência do modelo para analisar aprendizagem e desenvolvimento de competências no contexto empreendedor.

Assim, ao se analisar de que maneira o processo de aprendizagem, enquanto um processo experiencial possibilitou o conhecimento empreendedor, constatou-se que dois empreendedores apresentam equilíbrio entre o exploitation de conhecimentos pré-existentes e o exploration de novas possibilidades. Cinco empreendedores declararam que tem equilíbrio, entretanto, ao efetuar a análise de suas ações em confronto com a literatura abordada, percebese que há o predomínio de um dos modos: do exploration (E1, E2); e do exploitation (E3, E4, E7). Apenas dois empreendedores apontaram sua preferência e, com a análise, foi possível confirmálas. A maioria, sete entre nove, apresentou predomínio pelo modo exploitation, o que quer dizer que, neste estudo no setor educacional privado, foi possível confirmar que o modo predominante de transformação de um empreendedor modera sim a relação entre sua experiência de carreira e o conhecimento empreendedor (proposição 2) e que a confiança predominante num determinado modo tem relação com a efetividade do empreendedor em dada competência. Neste caso, a confiança predominante no modo exploitation está alinhada com a efetividade maior do empreendedor em lidar com a gestão de seu negócio (proposição $2 b$ ). Tal confirmação converge com a observação de que a experiência de carreira foi mais significativa no grupo pesquisado, e com a constatação de uma gama maior de conhecimentos relacionados à gestão em relação à oportunidade.

Quanto aos fatores que influenciam o processo de transformação de experiência de carreira em conhecimento empreendedor estão, segundo o modelo adotado, os resultados de eventos prévios, lógica ou racionalidade dominante e orientação de carreira (POLITIS, 2005).

\section{Fatores que Influenciam o Processo de Transformação}

De acordo com os relatos dos entrevistados, foi possível identificar que em cinco casos houve o predomínio da influência dos fracassos (E1, E5, E7, E8, E9) e em outro do sucesso (E2). Já o empreendedor E3 relatou que sua vida foi marcada somente por sucessos, pois "nunca regrediu financeiramente". Percebe-se que dentre os cinco entrevistados que apontaram o predomínio da influência dos fracassos, somente dois anunciaram que o maior grau de processo de transformação é o exploration, enquanto que os outros dois falaram em exploitation e um falou nos dois modos em equilíbrio. Percebe-se então, que neste estudo, a proposição $3 a$ de Politis (2005), que relaciona grau de fracasso passado com maior grau de modo explorative, não pode ser confirmada. Já entre os que anunciaram o sucesso, que são dois (E2 e E3), um apontou exploration como modo predominante e o outro apontou exploitation em maior grau. Portanto, não foi possível obter algum padrão para confirmar a proposição $3 b$ também, que relaciona o grau de sucesso passado com um maior grau de modo exploitative de transformar experiência em conhecimento.

Outro fator que exerce influência no processo de transformação e que foi destacado pelos 
entrevistados foi a lógica ou racionalidade dominante. Neste caso, houve predomínio da causação (E3, E4, E5, E8), seguida pela efetuação (E2, E7, E9) e em dois casos houve a causação e efetuação juntas (E1, E6); entretanto, percebeu-se uma intensidade maior na causação, tendo em vista que prevaleceu a utilização de metas pré-estabelecidas.

Com relação à proposição $4 a$, de que quanto maior a confiança na efetuação como racionalidade dominante maior é o grau do modo explorative de transformação, os resultados das análises apresentados na figura 3 demonstram que quatro empreendedores indicam a efetuação como lógica dominante (E2, E6, E7, E9), e entre eles um indica as duas lógicas, efetuação e causação (E6). Dentre eles, somente dois preferem exploration (E2, E9), um prefere os dois modos (E6) e um prefere o exploitation (E7). Neste caso, só é possível confirmar totalmente a relação da proposição em dois casos (E2, E9) e parcialmente em um (E6), sendo que em um deles, o E7, apesar da preferência pela lógica de efetuação, o modo predominante foi de exploitation.

Na proposição $4 b$, de que quanto maior a confiança na causação como racionalidade dominante, maior o grau do modo exploitative de transformar uma experiência em conhecimento, constatase que esta relação é mais constante, uma vez que dentre cinco que apontaram a confiança na causação (E1, E3, E4, E5 e E8), três apontaram grau maior no modo exploitation, sendo que o E8 apontou os dois modos exploitation e o exploration. Portanto, de nove casos pesquisados, em cinco deles foi possível confirmar esta proposição. Assim, estas proposições foram confirmadas parcialmente nestes casos.

No terceiro fator de influência, a orientação de carreira, encontrou-se o estilo especialista em seis casos (E1, E2, E3, E4, E5 e E6), linear em três (E3, E4, E7) e espiral em cinco (E1, E2, E6, E8, E9), sendo eles combinados em alguns empreendedores.

Percebe-se que há cinco casos com estilo espiral (E1, E2, E6, E8, E9). Destes, três apontaram seu foco no modo exploration e dois apontaram os dois modos. Então, pode-se confirmar a proposição $5 a$ em três casos totalmente (E1, E2, E9) e em dois se considerados ambos os modos (E6, E8). Neste caso a proposição 5a, de que empreendedores com uma orientação de carreira transitória ou espiral podem de forma mais ampla focar em um modo explorative de transformar uma experiência, parece ser mais claramente confirmada porque não houve casos contraditórios. Em suma, foram encontrados três casos com estilo linear (E3, E4, E7). Nestes três casos, todos apontaram os dois modos, mas com predomínio do exploitation, o que confirma a relação entre o estilo linear e o modo exploitation. Já quanto ao especialista, foram encontrados seis casos (E1, E2, E3, E4, E5, E6). Dentre estes, onde se esperaria um modo predominante exploitation também, somente três apontaram o predomínio dele (E3, E4, E5).

Entre os outros três, dois apontaram a preferência por exploration (E1, E2), e um pelo equilíbrio dos dois modos (E6). Neste caso, de forma geral, considerando o modo especialista e espiral, que estão relacionados ao modo exploitation, a confirmação da proposição $5 b$, de que empreendedores com uma orientação de carreira linear ou especialista podem de uma forma mais ampla focar em um modo exploitative de transformar uma experiência em conhecimento, só foi possível em quatro dos nove casos (E3, E4, E5, E7).

O quadro 01, apresentada a seguir, mostra uma síntese dos resultados encontrados nos nove casos estudados, considerando as dimensões do modelo adotado de Politis (2005). 


\begin{tabular}{|c|c|c|c|c|c|c|c|c|c|}
\hline \multirow{2}{*}{$\begin{array}{l}\mathrm{E} \\
\mathrm{m} \\
\mathrm{p} \\
\mathrm{r} \\
\mathrm{e} \\
\mathrm{s} \\
\mathrm{a} \\
\mathrm{s}\end{array}$} & \multicolumn{3}{|c|}{$\begin{array}{l}\text { Experiências de Carreira } \\
\text { Empreendedora }\end{array}$} & \multicolumn{2}{|c|}{ Conhecimento Empreendedor } & \multirow{2}{*}{$\begin{array}{l}\text { Processo de } \\
\text { Transfor- } \\
\text { mação }\end{array}$} & \multicolumn{3}{|c|}{$\begin{array}{c}\text { Fatores que influenciam o } \\
\text { Processo de Transformação }\end{array}$} \\
\hline & $\begin{array}{l}\text { Criaç } \\
\text { Emp. }\end{array}$ & $\begin{array}{l}\text { Adm. } \\
\text { Emp. }\end{array}$ & $\begin{array}{l}\text { Setor } \\
\text { Educac. }\end{array}$ & $\begin{array}{l}\text { Reconhecer } \\
\text { Oportunid. }\end{array}$ & $\begin{array}{l}\text { Lidar Resp. } \\
\text { Novo Negócio }\end{array}$ & & $\begin{array}{l}\text { Result. } \\
\text { Event. } \\
\text { Prévios } \\
*\end{array}$ & $\begin{array}{c}\text { Lógic } \\
\text { aDom } \\
\text { in } \\
* * *\end{array}$ & $\begin{array}{c}\text { Orient } \\
\text { Carreira }\end{array}$ \\
\hline $\begin{array}{l}\mathbf{E} \\
\mathbf{1}\end{array}$ & \multicolumn{2}{|c|}{$\begin{array}{l}\text { Empresa de } \\
\text { Alarmes }\end{array}$} & - & $\begin{array}{l}\text { Ampliação } \\
\text { física } \\
\text { Escola } \\
\text { integral em } \\
\text { um sítio }\end{array}$ & $\begin{array}{l}\text { PPP; Regimento; } \\
\text { Planejamento } \\
\text { Adm. Escolar; } \\
\text { Gestão Pessoas }\end{array}$ & $\begin{array}{l}\text { Exploitation } e \\
\text { Exploration* }\end{array}$ & S e $F^{*}$ & $\mathrm{C}^{*}$ e E & $\begin{array}{l}\text { Espec. e } \\
\text { Espiral }\end{array}$ \\
\hline $\begin{array}{l}\mathbf{E} \\
2\end{array}$ & - & - & $\begin{array}{l}\text { Professor } \\
\text { Municip. } \\
\text { Diretora } \\
\text { Municip. }\end{array}$ & $\begin{array}{l}\text { Ensino } \\
\text { Fundamental } \\
\text { Cursos à } \\
\text { Distância }\end{array}$ & $\begin{array}{l}\text { PPP; Regimento; } \\
\text { Adm. Escolar; } \\
\text { Gestão Pessoas }\end{array}$ & $\begin{array}{l}\text { Exploitation } e \\
\text { Exploration * }\end{array}$ & $\mathrm{S}^{*}$ e F & E & $\begin{array}{l}\text { Espec. e } \\
\text { Espiral }\end{array}$ \\
\hline $\begin{array}{l}\mathbf{E} \\
\mathbf{3}\end{array}$ & \multicolumn{2}{|c|}{$\begin{array}{l}\text { Escritório de } \\
\text { Arquitetura }\end{array}$} & $\begin{array}{l}\text { Professor } \\
\text { Pró-Vida }\end{array}$ & - & $\begin{array}{l}\text { Adm. Escolar; } \\
\text { Gestão Pessoas }\end{array}$ & $\begin{array}{l}\text { Exploitation* } \\
\text { Exploration }\end{array}$ & $\mathrm{S}$ & $\mathrm{C}$ & $\begin{array}{l}\text { Espec. e } \\
\text { Linear }\end{array}$ \\
\hline $\begin{array}{l}\mathbf{E} \\
4\end{array}$ & \multicolumn{2}{|c|}{$\begin{array}{l}\text { Escritório de } \\
\text { Advocacia }\end{array}$} & $\begin{array}{l}\text { Professor } \\
\text { Pública } \\
\text { Coord / } \\
\text { Superv. } \\
\text { Pública }\end{array}$ & $\begin{array}{l}\text { Cursos Livres } \\
\text { (UC) } \\
\text { Ensino Médio }\end{array}$ & $\begin{array}{l}\text { Adm. Escolar; } \\
\text { Gestão Pessoas; } \\
\text { Finanças; } \\
\text { Planejamento }\end{array}$ & $\begin{array}{l}\text { Exploitation* } \\
\text { Exploration }\end{array}$ & S e F & $\mathrm{C}$ & $\begin{array}{l}\text { Espec. e } \\
\text { Linear }\end{array}$ \\
\hline $\begin{array}{l}\mathbf{E} \\
\mathbf{5}\end{array}$ & - & Igreja & $\begin{array}{l}\text { Professor } \\
\text { Escola } \\
\text { Partic. }\end{array}$ & $\begin{array}{l}\text { Ensino } \\
\text { Fundamental } \\
\text { Festas } \\
\text { Infantis }\end{array}$ & $\begin{array}{l}\text { PPP; Regimento; } \\
\text { Adm. Escolar; } \\
\text { Gestão Pessoas; } \\
\text { Finanças; } \\
\text { Contabilidade }\end{array}$ & Exploitation & S e $F^{*}$ & $\mathrm{C}$ & Espec. \\
\hline $\begin{array}{l}E \\
6\end{array}$ & - & - & $\begin{array}{l}\text { Aulas } \\
\text { Particul. } \\
\text { Atenden. } \\
\text { Creche } \\
\text { Hospital } \\
\text { Professor } \\
\text { Escola } \\
\text { Particul. }\end{array}$ & Berçário & $\begin{array}{l}\text { PPP; Regimento; } \\
\text { Adm. Escolar; } \\
\text { Gestão Pessoas; } \\
\text { Planejamento; } \\
\text { Finanças; } \\
\text { Contabilidade }\end{array}$ & $\begin{array}{l}\text { Exploitation e } \\
\text { Exploration }\end{array}$ & S e F & C e E & $\begin{array}{l}\text { Espec. e } \\
\text { Espiral }\end{array}$ \\
\hline $\begin{array}{l}\mathbf{E} \\
7\end{array}$ & - & - & - & $\begin{array}{l}\text { Melhorias na } \\
\text { estrutura } \\
\text { Foco nicho } \\
\text { Consolidação } \\
\text { diferencial da } \\
\text { escola }\end{array}$ & $\begin{array}{l}\text { PPP; Regimento; } \\
\text { Adm. Escolar; } \\
\text { Gestão Pessoas }\end{array}$ & $\begin{array}{l}\text { Exploitation* } \\
\text { Exploration }\end{array}$ & S e F* & E & Linear \\
\hline $\begin{array}{l}\mathbf{E} \\
\mathbf{8}\end{array}$ & - & - & $\begin{array}{l}\text { Professor } \\
\text { Escola } \\
\text { Partic. } \\
\text { Prof. } \\
\text { Universi- } \\
\text { tária }\end{array}$ & $\begin{array}{l}\text { Atendimento } \\
\text { individualiza } \\
\text {-do } \\
\text { Ampliação } \\
\text { física }\end{array}$ & $\begin{array}{l}\text { PPP; Regimento; } \\
\text { Adm. Escolar; } \\
\text { Gestão Pessoas; } \\
\text { Planejamento; } \\
\text { Contabilidade; } \\
\text { Marketing }\end{array}$ & $\begin{array}{c}\text { Exploitation e } \\
\text { Exploration }\end{array}$ & S e $F^{*}$ & $\mathrm{C}$ & Espiral \\
\hline
\end{tabular}


Quadro 01 - Aprendizagem empreendedora

Fonte: Pesquisa de dados (2009).

* Predomínio deste fator

** $\mathrm{S}=$ Sucesso e $\mathrm{F}=$ Fracasso

*** C = Causação e E = Efetuação

Neste estudo foi possível confirmar a teoria de Politis (2005), pois aqueles empreendedores que tinham maior experiência de carreira e melhor souberam aproveitá-las e aplicá-las em seus empreendimentos, a transformaram em um leque maior de conhecimentos, habilidades e atitudes, os quais resultaram no desenvolvimento das competências de oportunidade e administrativa, como se pode verificar na figura 3. Portanto, constatou-se como resultado do processo de transformação, o desenvolvimento de uma competência de reconhecer oportunidades num nível médio e circunscrito ao próprio negócio, pois os empreendedores dessa área tendem a investir no próprio setor. Constatou-se também o desenvolvimento de uma competência administrativa, a qual foi avaliada tanto pelos empreendedores como pela pesquisadora, como mais elevada.

Ao integrar os modelos de Politis (2005) e de Man e Lau (2000) neste estudo, focando no processo de transformação de experiências em conhecimentos, habilidades e atitudes, constatou-se que o resultado foi o desenvolvimento de competências de oportunidade e administrativas dos empreendedores entrevistados.

\section{Considerações Finais e Revisão do Modelo de Pesquisa}

O presente estudo visou analisar de que maneira os proprietários/dirigentes de MPE's do setor educacional privado do município de Curitiba-Pr desenvolveram as competências empreendedoras de oportunidade e administrativa por meio de um processo de aprendizagem. Para tal, adotou-se como modelo conceitual de pesquisa, os modelos de aprendizagem empreendedora de Politis (2005) e o de competências empreendedoras de Man e Lau (2000), mais especificamente quanto às competências de oportunidade e administrativa.

Os próprios empreendedores, tendo por base os concorrentes na área educacional classificaram o seu posicionamento em ambas as competências entre na média e muito alta. 0 resultado apontou para o desenvolvimento das duas competências em todos os casos, os quais variaram de intensidade de acordo com as experiências e os conhecimentos (POLITIS, 2005).

Com as histórias de vida narradas pelos empreendedores observou-se que a maioria deles (sete) possui experiência de carreira prévia. Três deles já tinham criado outras empresas e uma delas teve experiência com gestão ao administrar uma igreja. Os demais empreendedores trabalharam anteriormente na área de educação e também como diretores de escolas públicas. Assim, as duas primeiras proposições de Politis (2005) relacionadas à experiência de carreira do empreendedor, em termos de criação de empresas, gestão e experiência específica do setor, foram confirmadas.

Identificou-se que os empreendedores aprendem por meio do processo experiencial, ou seja, com as práticas diárias, as experiências, a observação, educação formal, leituras, entre outros. Investigou-se o processo de transformação das experiências em conhecimento e verificou-se que sete entre nove apresentaram predomínio do modo exploitation. Isto quer dizer que, neste estudo se pode confirmar que o modo predominante de transformação de um empreendedor modera sim a relação entre sua experiência de carreira e o conhecimento empreendedor (proposição 2). Neste caso, a confiança predominante no modo exploitation está alinhada com a efetividade maior do empreendedor em lidar com a gestão de seu negócio (proposição $2 \mathrm{~b}$ ). Tal 
confirmação converge com a observação de que a experiência de carreira foi mais significativa com os aspectos da gestão em relação aos da oportunidade.

Com relação aos fatores que influenciam os empreendedores nesse processo de transformação, verificou-se que nos eventos prévios houve destaque para os sucessos e fracassos. As terceiras proposições de Politis (2005) de que o resultado de eventos prévios de um empreendedor está relacionado ao seu modo de transformar uma experiência em conhecimento, não puderam ser comprovadas neste estudo. Quanto à lógica ou racionalidade dominante, as proposições quatro de Politis (2005), foram confirmadas parcialmente nestes casos. Na orientação de carreira, observou-se que em alguns casos a proposição não pode ser claramente confirmada porque mais de um estilo foi apontado pelos entrevistados.

Aplicando o modelo conceitual no estudo foi possível demonstrar a ligação entre a experiência de carreira e o desenvolvimento dos conhecimentos, através da análise do modo predominante do empreendedor fazer essa transferência e dos fatores que o influenciaram. A análise desse percurso permitiu finalmente, a constatação do desenvolvimento das duas competências como resultado do processo de aprendizagem empreendedora.

Quanto à competência de oportunidade que está relacionada ao reconhecimento de novas oportunidades, constatou-se que os empreendedores os identificam especificamente na área de atuação. Percebeu-se também que a competência administrativa teve uma avaliação ligeiramente superior a de oportunidade, o que pode ser considerado como uma característica do setor educacional em que os empreendedores permanecem por longo tempo na atividade, pois tem uma afinidade 'vocacional' com o ramo em que atuam (TAKAHASHI, GRAEFF e TEIXEIRA, 2006), e que talvez estejam mais preocupados em cuidar da administração do negócio e do crescimento do que em explorar novas oportunidades. Isto explicaria porque eles adquirem maiores conhecimentos relativos à competência de gestão do negócio, mais eficiente na capacidade de lidar com as responsabilidades da rotina educacional.

Mediante tais resultados, acredita-se que o objetivo geral da pesquisa foi atingido. As contribuições deste estudo para a área de conhecimento consistiram na aplicação do modelo de aprendizagem empreendedora de Politis (2005) no setor educacional brasileiro; na realização de uma pesquisa teórico-empírica sobre aprendizagem e competências empreendedoras em

MPE's; na integração das teorias de aprendizagem empreendedora (POLITIS, 2005) e competências empreendedoras (MAN e LAU, 2000) e em focar no processo de transformação de experiências em conhecimento empreendedor. Com relação aos empreendedores, para as MPE's do setor educacional, as contribuições incidiram no avanço dos estudos teórico-empíricos relacionados à gestão dos empreendimentos e ao reconhecimento de novas oportunidades.

Por fim, esta pesquisa também permitiu rever o modelo adotado e sugerir algumas alterações. Observou-se que as frases utilizadas na dimensão 'conhecimento empreendedor' mais se aproximam, segundo a literatura, de denominações de competências do que de conhecimentos em si. Considerando que competências e conhecimentos são categorias diferentes e que a primeira integra a segunda, tais frases situar-se-iam melhor no quadrante de competências. Desta forma, na dimensão de conhecimento, que poderia ser estendida a habilidade, atitudes e outros itens que compõe uma competência, poderiam ser citados os respectivos dados encontrados quanto à oportunidade e gestão. Assim, o aprimoramento do modelo de aprendizagem empreendedora de Politis (2005), integrado ao modelo de competências relacionadas a oportunidades e gestão, pode ser observado na figura 4 . A análise desse 
percurso permite então a identificação do desenvolvimento de competências considerando-as como resultado de um processo de aprendizagem (D).

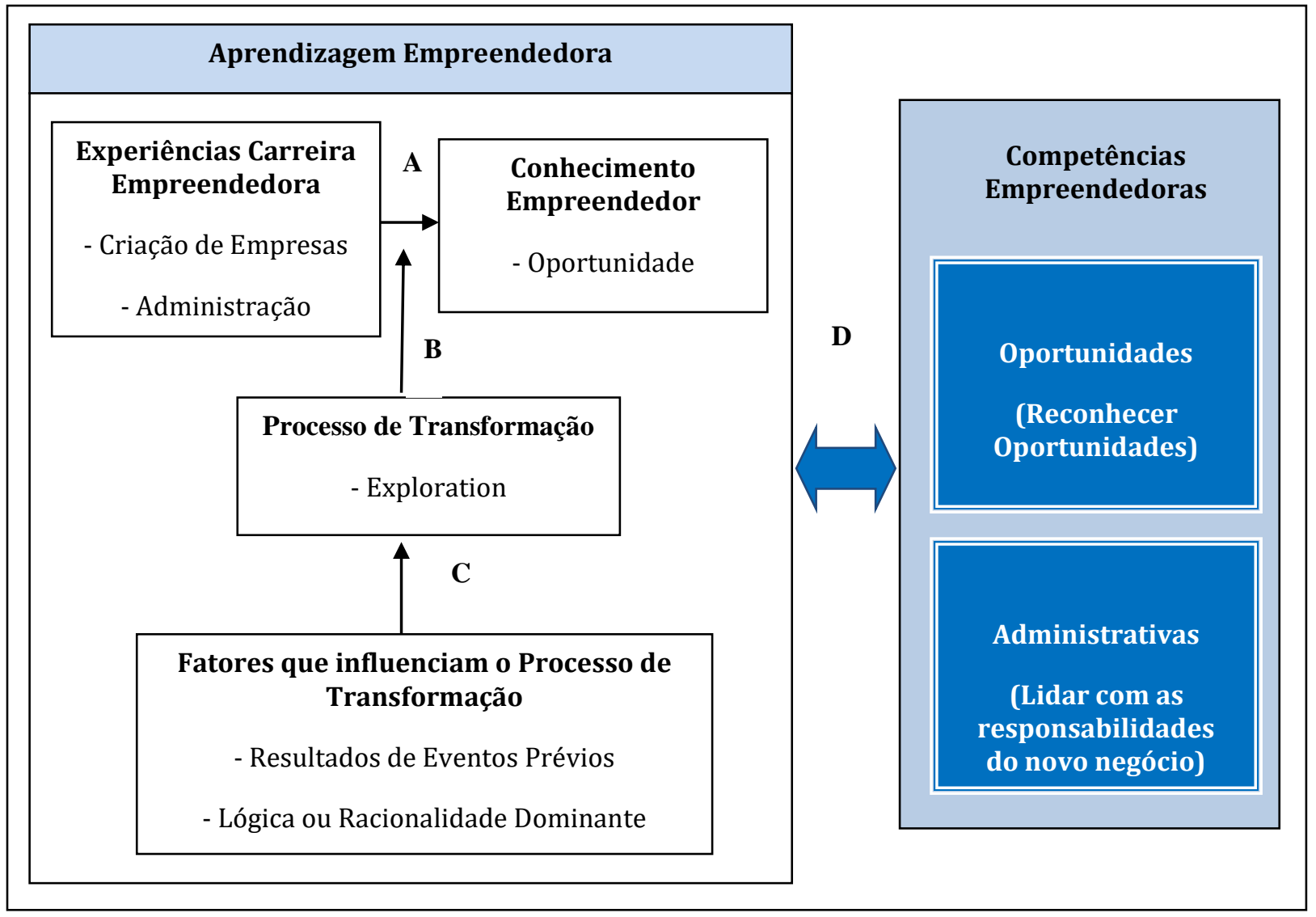

Figura 03- Modelo de aprendizagem empreendedora aprimorado

Fonte: Adaptado de Politis (2005) e Man e Lau (2000).

Visando à continuidade e aprofundamento dos estudos no campo de aprendizagem, conhecimento e competências no contexto empreendedor, sugere-se a realização de pesquisas futuras que permitam replicar o estudo em outros setores, ampliando o número de entrevistados em cada caso, realizando estudos de casos longitudinais. Outra sugestão é incluir fatores que possibilitem analisar o grau de complexidade das competências desenvolvidas e o grau de entrega realizada pelos empreendedores aos seus negócios.

\section{Referências}

ANTAL, A. B.; et al. Organizational learning and knowledge: reflections on the dynamics of the field and challenges for the future. In: DIERKES, M. et al. (Orgs.) Handbook of Organizational Learning \& Knowledge. Oxford: Oxford University Press, p. 921-939, 2001.

ANTONELLO, C. S. A metamorfose da aprendizagem organizacional: Uma revisão crítica. In: RUAS, R. L.; ANTONELLO, C. S.; BOFF, L. H. e colaboradores. Os Novos Horizontes da Gestão: aprendizagem organizacional e competências. Porto Alegre: Bookman, p. 12-33, 2005.

BARINI FILHO, U. Transmissão da competência empreendedora: Um estudo de casos múltiplos. Tese (Doutorado) - Universidade de São Paulo, 2008. 
BITEnCOURT, C. C. Gestão de Competências e Aprendizagem nas Organizações. São Leopoldo/RS: Unisinos, 2005.

COLLIS, J.; HUSSEY, R. Pesquisa em Administração: um guia prático para alunos de graduação e pós-graduação. 2. ed. Porto Alegre: Bookman, 2005.

COOLEY, L. Entrepreneurship Training and the Strengthening of Entrepreneurial Performance. Final Report. Contract No. DAN-5314-C-00-3074-00. Washington: USAID, 1990.

COOPER, D. R.; SCHINDLER, P. S. Métodos de Pesquisa em Administração. Porto Alegre: Bookman, 2003.

CRESWELL, J. W. Projeto de Pesquisa: métodos qualitativo, quantitativo e misto. 2. ed. Porto Alegre: Artmed, 2007.

DIAS, T. R. F. V.; NARDELLI, P. M.; VILAS BOAS, A. A. Competências empreendedoras: Um estudo sobre os empreendedores ganhadores do prêmio TOP Empresarial. In: ENCONTRO DE ESTUDOS SOBRE EMPREENDEDORISMO E GESTÃO DE PEQUENAS EMPRESAS, 2008, São Paulo, Anais... São Paulo: 2008.

DUTRA, J. S. Competências: conceitos e instrumentos para a gestão de pessoas na empresa moderna. São Paulo: Atlas, 2004.

ESPEJO, M. M. S. B.; PREVIDELLI, J. J. Os grandes desafios e as estratégias do empreendedor no ensino superior privado. In: PREVIDELLI, J. J.; SELA, V. M. (Org.).

Empreendedorismo e Educação Empreendedora. Maringá/Pr: Unicorpore, p. 21-52, 2006.

FEUERSCHÜTTE, S. G.; ALPERSTEDT, G. D. Empreendedorismo e competência: Um ensaio sobre a complementaridade e a convergência dos construtos. In: ENCONTRO DA ASSOCIAÇÃO NACIONAL DE PÓS-GRADUAÇÃO E PESQUISA EM ADMINISTRAÇÃO, Rio de Janeiro, 2008. Anais... Rio de Janeiro: 2008.

FEUERSCHÜTTE, S. G.; GODOI, C. K. Competências empreendedoras: Um estudo historiográfico no setor hoteleiro. In: ENCONTRO DA ASSOCIAÇÃO NACIONAL DE PÓS-GRADUAÇÃO E PESQUISA EM ADMINISTRAÇÃO, 2007, Rio de Janeiro, Anais... Rio de Janeiro: 2007.

FREITAS, I. A. de.; BRANDÃO, H. P. Trilhas de aprendizagem como estratégias de TD\&E. In: BORGES-ANDRADE, J. E.; ABBAD, G. DA S.; MOURÃO, L. Treinamento, Desenvolvimento e Educação em Organizações e Trabalho: fundamentos para a gestão de pessoas. Porto Alegre: Artmed, p. 97-113, 2006.

GLOBAL ENTREPRENEURSHIP MONITOR - GEM 2008. Global Entrepreneurship Monitor 2008 - Empreendedorismo no Brasil. Curitiba: IBPQ, 2009.

GODOY, A. S. Estudo de caso qualitativo. In: GODOI, C. K.; BANDEIRA-DE-MELLO; SILVA, A. B. da. (Org.). Pesquisa Qualitativa em Estudos Organizacionais: paradigmas, estratégias e métodos. São Paulo: Saraiva, p. 115-146, 2006.

HOLCOMB, T. R.; et al. Architecture of entrepreneurial learning: exploring the link among 
heuristics, knowledge, an action. Entrepreneurship Theory and Practice, p. 167-192, 2009.

KUCKERTZ, A. What's Hot in Entrepreneurship Research 2013? Apresentação dos resultados da pesquisa em Conferência, Essen, 2013. Disponível em < https://entrepreneurship.unihohenheim.de/whats-hot-english?\&L=1> Acesso em 12.12.2013.

LE BOTERF, G. Desenvolvendo a Competência dos Profissionais. Porto Alegre: Artmed, 2003.

LÉVESQUE, M.; MINNITI, M.; SHEPHERD, D. Entrepreneurs' decisions on timing of entry: learning from participation and from the experiences of others. Entrepreneurship Theory and Practice, p. 547-570, 2009.

LEZANA, A. G. R.; TONELLI, A. 0 Comportamento do Empreendedor. Florianópolis: Escola de Novos Empreendedores, 1998.

MAMEDE, M. I. de B.; MOREIRA, M. Z. Perfil de competências empreendedoras dos investidores Portugueses e Brasileiros: Um estudo comparativo na rede hoteleira do Ceará. In: ENCONTRO DA ASSOCIAÇÃO NACIONAL DE PÓS-GRADUAÇÃO E PESQUISA EM ADMINISTRAÇÃO, 2005, Brasília, Anais...Brasília: 2005.

MAN, T. W. Y. Exploring the behavioural patterns of entrepreneurial learning: a competency approach. Education e Training, v. 48, n. 5, p. 309-321, 2006.

MAN, T. W. Y.; LAU, T. Entrepreneurial competencies of SME owner/managers in the Hong Kong services sector: a qualitative analysis. Journal of Enterprising Culture, v. 8, n. 3., p. 235-254, 2000.

MARCH, J. Exploration and exploration in organizational learning. Organization Science, v. 2, n. $1,1991$.

MORAES, L. V. S.; HOELTGEBAUM, M. Um modelo para a análise do processo de aprendizagem de empreendedores. In: Third International Conference of the Iberoamerican Academy of Management, 2003, São Paulo, Anais... São Paulo: 200.

MORRISON, A.; BERGIN-SEERS, S. Pro-Growth small businesses: learning "Architecture". Journal of Management Development, v. 21, n. 5, p. 388-400, 2002.

NEUMAN, W. L. Social Research Methods: qualitative and quantitative approaches. 3. ed. Boston: Allyn and Bacon, 1999.

POLITIS, D. Does prior start-up experience matter for entrepreneurs' learning? a comparison between novice and habitual entrepreneurs. Journal of Small Business and Enterprise Development,v.15,n.3,p.472-489, 2008.

POLITIS, D. The process of entrepreneurial learning: a conceptual framework. Entrepreneurship Theory and Practice, p. 399-424, 2005.

POLITIS, D. ; GABRIELSSON, J. Entrepreneurial decision making: examining preferences for causal and effectual reasoning in the new venture creation process. Lund Institute of Economic Research: Working Paper Series, 2006. 
POLITIS, D.; GABRIELSSON, J. Exploring the role of experience in the process $\mathrm{f}$ entrepreneurial learning. Lund Institute of Economic Research: Working Paper Series, 2005.

RAE, D. Entrepreneurial learning: A narrative-based conceptual model. Journal of Small Business and Enterprise Development, v. 12, n. 2, p. 323-335, 2005.

RAE, D. Entrepreneurial learning: A practical model from the creative industries. Education + Training, v. 46, n. 8/9, p. 492-500, 2004.

SARASVATHY, S. D. Causation and effectuation: Toward a theoretical shift from economic inevitability to entrepreneurial contingency. Academy of Management Review, v. 26, n. 2, p. 243-288, 2001.

SNELL, R.; LAU, A. Exploring local competences salient for expanding small business. Journal of Management Development, v. 13, n.4, 1994.

SERVIÇO BRASILEIRO DE APOIO ÀS MICROS E PEQUENAS EMPRESAS - SEBRAE. Anuário do trabalho na micro e pequena empresa: 2008. Brasília, DF: DIEESE, 2008.

TAKAHASHI, A. R. W.; GRAEFF, J. F.; TEIXEIRA, R. M. Planejamento estratégico e gestão feminina em pequenas empresas: 0 caso das escolas particulares em Curitiba/Paraná. 0 \& S, v. 13, n. 39, p. 29-44, 2006.

WANG, C.; CHUGH, H. Entrepreneurial learning: past research and future challenges. International Journal of Management Reviews, p. 1-38, 2013.

WEICK, K. E.; WESTLEY, F. Organizational learning: affirm an oxymoron. In: GLEGG, S. et al. (Orgs.). Handbook of Organizational Studies. Londres: Sage, p. 440-458, 1996.

YIN, R. K. Estudo de Caso: planejamento e métodos. Porto Alegre: Bookman, 2010.

ZAMPIER, M. A.; TAKAHASHI, A. R. W.; FERNANDES, B. H. R. Sedimentando as bases de um conceito: As competências empreendedoras. In COLÓQUIO SOBRE EMPREENDEDORISMO E ESTRATÉGIA DE EMPRESAS DE PEQUENO PORTE, 2009, Curitiba, Anais... Curitiba: 2009. 